\title{
Helix-Sense-Selective and Enantiomer-Selective Polymerization of a Chiral Methacrylate by Anionic and Free-Radical Mechanisms
}

\author{
Tamaki NaKano, Naotaka Kinjo, Yasuaki Hidaka, \\ and Yoshio OKaмото \\ Department of Applied Chemistry, Graduate School of Engineering, Nagova University, \\ Furo-cho, Chikusa-ku, Nagoya 464-8603, Japan
}

(Received December 9, 1998)

\begin{abstract}
O-Isopropylidene-trans-10,11-dihydroxy-5-phenyl-10,11-dihydro-5H-dibenzo[a,d]cycloheptene5-yl methacrylate (IDPDMA) was synthesized and resolved into an optically pure form by chiral HPLC. Anionic polymerization of IDPDMA was carried out using the complexes of $N . N^{\prime}$-diphenylethylenediamine monolithium amide (DPEDA-Li) with (+)-1-(2-pyrrolidinylmethyl)pyrrolidine, (+)-2.3-dimethoxy-1.4-bis(dimethylamino)butane, and (-)-sparteine in toluene at $-78 \mathrm{C}$ or using DPEDA- $\mathrm{Li}$ in tetrahydrofuran at $-78 \mathrm{C}$. The polymers obtained from the racemic monomer using the chiral initiators and the polymer obtained from $(+)$-monomer under the achiral condition appeared to have a helical conformation with excess helicity. The polymerizations of ( \pm )-IDPDMA using the chiral initiators were enantiomer-selective: $(+)$-monomer was preferentially polymerized. Free-radical polymerization of optically active IDPDMA having various enantiomeric excesses using $\gamma_{.} x^{\prime}$-azobisisobutyronitrile in toluene at $60 \mathrm{C}$ gave almost completely isotactic polymers which probably had a helical conformation with excess helicity. Enantiomer selection was also confirmed in the radical polymerization.

KEY WORDS Methacrylate/Radical Polymerization/Helix/Enantiomer Selection
\end{abstract}

Bulky methacrylates including triphenylmethyl methacrylate (TrMA) and 1-phenyldibenzosuberyl methacrylate (PDBSMA) afford single-handed helical, highly isotactic polymers by asymmetric anionic polymerization using chiral organolithium complexes as initiators (helixsense-selective polymerization), ${ }^{1.2}$ and the polymers show chiral recognition ability toward a wide range of racemic compounds. ${ }^{3.4}$ PDBSMA is an especially interesting one among such bulky monomers because it gives an almost completely isotactic polymer (an equimolar mixture of right- and left-handed helices) even by free-radical polymerization regardless of reaction conditions $^{5-7}$ as well as by anionic polymerization ${ }^{8}$ while free-radical polymerization of common vinyl monomers in solution generally has poor control of stereochemistry. ${ }^{9.10}$ Taking advantage of this high stereospecificity of the PDBSMA polymerization, we have succeded in obtaining poly(PDBSMA)s with excess right- or left-handed helicity by free-radical mechanism using optically active initiators, chain transfer agents, solvents, or a free-radical metallic species. ${ }^{7,11}$

In the present work, we synthesized racemic $( \pm)$ 10,11-O-isopropylidene-trans-10,11-dihydroxy-5-phenyl10,1 1 -dihydro-5 H-dibenzo $[a, d]$ cycloheptene-5-yl methacrylate (IDPDMA), which is a chiral analogue of PDBSMA, resolved it into an optically pure form by chiral HPLC, and investigated the stereochemistry of anionic and free-radical polymerizations of the racemic and the optically active monomers. In the polymerization

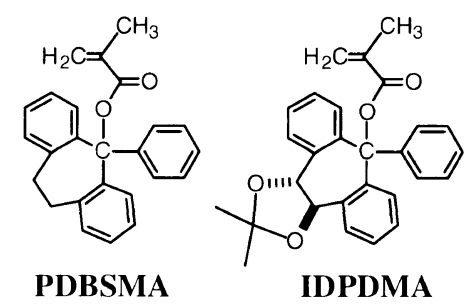

of a chiral bulky monomer, helix-sense selection based on the chirality of monomer itself and enantiomer selection can take place. ${ }^{1.2}$ IDPDMA was designed based on the PDBSMA structure in search of monomers which enables helix-sense-selective and enantiomer-selective polymerization not only by anionic mechanism but also by free-radical mechanism.

\section{EXPERIMENTAL}

\section{Materials}

PDBSMA was available from our previous work. ${ }^{5-7}$ Bromobenzene (Tokyo Chemical Industry) was dried on $\mathrm{CaH}_{2}$ and distilled under reduced pressure immediately before use. Dibenzosuberenone $(5 H$-dibenzo $[a, d]$ cyclohepten-5-one) (1) (Aldrich) was used as obtained. Diethyl ether and tetrahydrofuran (THF) were distilled over $\mathrm{Na}$ wire and stored under nitrogen in the dark. $\mathrm{HClO}_{4}(60 \%$ water solution) (Nakalai) was used as received. Purification of the other materials including those for anionic polymerization has been shown in the literatures. ${ }^{12.13}$

\section{Sinthesis of IDPDMA}

IDPDMA monomer was synthesized as shown in Scheme 1 starting from 1.

10,11-Epoxy-10,11-dihydro-5H-dibenzo[a,d]cyclohepten-5-one ${ }^{14.15}(\mathbf{2})$ was prepared by epoxidation of $\mathbf{1}$ under air. 1 ( $199 \mathrm{~g}, 0.486 \mathrm{~mol}$ ) was dissolved in $\mathrm{CH}_{2} \mathrm{Cl}_{2}$ in a $2-\mathrm{L}$ flask, and the solution was cooled to $0^{\circ} \mathrm{C}$ and kept in the dark. $m$-Chloroperoxybenzoic acid $(100 \mathrm{~g}$, $0.486 \mathrm{~mol}$ ) was added to the solution. After the mixture was homogenized, a water (11) solution of $\mathrm{NaHCO}_{3}$ $(61.2 \mathrm{~g}, 0.729 \mathrm{~mol})$ was added, and the mixture was stirred at $0{ }^{\circ} \mathrm{C}$ for $24 \mathrm{~h}$ in the dark. At this point, ${ }^{1} \mathrm{H} \mathrm{NMR}$ analysis of the reaction mixture revealed that c $a .50 \%$ of the ketone remained in the reaction system while $m$-chloroperoxybenzoic acid was completely consumed. $m$-Chloroperoxybenzoic acid $(50 \mathrm{~g}, 0.243 \mathrm{~mol})$ and a 

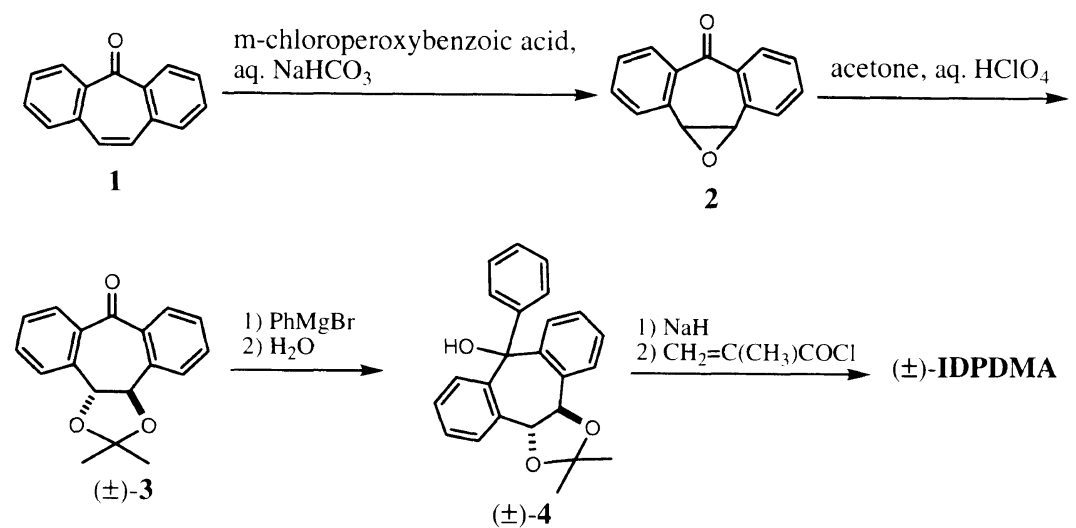

Scheme 1. Synthesis of ( \pm )-IDPDMA.

water $(500 \mathrm{ml})$ solution of $\mathrm{NaHCO}_{3}(30.0 \mathrm{~g}, 0.357 \mathrm{~mol})$ were added to the reaction system and the mixture was stirred for $48 \mathrm{~h}$. After the complete consumption of the ketone was confirmed by NMR and TLC analyses, the product was extracted using $\mathrm{CH}_{2} \mathrm{Cl}_{2}$-saturated aq $\mathrm{NaCl}$. The organic layer was dried on $\mathrm{Na}_{2} \mathrm{SO}_{4}$, and removal of $\mathrm{CH}_{2} \mathrm{Cl}_{2}$ under reduced pressure gave a crude oily product. Recrystallization of the crude product from diethyl ether gave colorless crystals. Yield $54.0 \mathrm{~g}(50 \%)$. mp $94.0-97.5^{\circ} \mathrm{C}$ (lit. $\left.{ }^{14} 100-105^{\circ} \mathrm{C}\right) .{ }^{1} \mathrm{H}$ NMR $(400$ $\left.\mathrm{MHz}, \mathrm{CDCl}_{3}, \mathrm{Me}_{4} \mathrm{Si}\right) \delta 7.63,7.56,7.52,7.44(\mathrm{~d}, \mathrm{~d}, \mathrm{t}, \mathrm{t}$, $2 \mathrm{H}$ for each, aromatic $\mathrm{H}), 4.46\left(\mathrm{~s}, 2 \mathrm{H},-\mathrm{CH}_{2} \mathrm{CH}_{2}-\right)$. IR (KBr) $1661 \mathrm{~cm}^{-1}(\mathrm{C}=\mathrm{O})$. FD Mass $m / z=222.1$ (calcd 222.1)

( \pm )-10,11-O-Isopropylidene-trans-10,11-dihydroxy10,11-dihydro-5 $H$-dibenzo $[a, d]$ cyclohepten-5-one ${ }^{16,17}$ (3) was synthesized as follows. The reaction was performed under air. 2 (40 g, $0.18 \mathrm{~mol})$ was dissolved in acetone $(660 \mathrm{ml}, 9 \mathrm{~mol})$. A small amount of acetoneinsoluble part was removed by filtration using Celite. To the solution was added aq $\mathrm{HClO}_{4}(30.2 \mathrm{ml}, 0.180 \mathrm{~mol})$ in the dark, and the mixture was stirred for $24 \mathrm{~h}$. The reaction was terminated by adding a water $(200 \mathrm{ml})$ solution of $\mathrm{NaHCO}_{3}(22.7 \mathrm{~g}, 0.270 \mathrm{~mol})$ and the products were extracted using diethyl ether-saturated aq $\mathrm{NaCl}$. The organic layer was dried on $\mathrm{Na}_{2} \mathrm{SO}_{4}$, and the solvent was removed under reduced pressure. The residue was dissolved in $\mathrm{CHCl}_{3}$ and a small amount of insoluble part (inorganic salts) was removed by filtration using Celite. Removal of the solvent from the $\mathrm{CHCl}_{3}$-soluble part gave the crude product. Yield $40 \mathrm{~g}(80 \%)$. The crude product was purified by column chromatography (stationary phase $=$ activated alumina 300 mesh, eluent $=$ diethyl ether-hexane $(1: 1, \mathrm{v} / \mathrm{v}))$. Yield $19 \mathrm{~g} \mathrm{(37 \% ).} \mathrm{mp}$ $89.5-90.5 \mathrm{C}$ (lit. $\left.{ }^{16} 99-100^{\circ} \mathrm{C}\right) .{ }^{1} \mathrm{H}$ NMR $(400 \mathrm{MHz}$, $\left.\mathrm{CDCl}_{3}, \mathrm{Me}_{4} \mathrm{Si}\right) \delta 8.18,7.74,7.60,7.44(\mathrm{~d}, \mathrm{~d}, \mathrm{t}, \mathrm{t}, 2 \mathrm{H}$ for each, aromatic $\mathrm{H}), 5.11(\mathrm{~s}, 2 \mathrm{H},-\mathrm{CHCH}-), 1.61(\mathrm{~s}, 6 \mathrm{H}$, $\left.\mathrm{CH}_{3}\right)$. IR $(\mathrm{KBr}) 1643 \mathrm{~cm}^{-1}(\mathrm{C}=\mathrm{O})$. FD Mass $m / z=$ 280.1 (calcd 280.1).

( \pm )-10,11-O-Isopropylidene-trans-10,11-dihydroxy5-phenyl-10,11-dyhydro-5 $\mathrm{H}$-dibenzo $[a, d]$ cyclohepten5-ol (4) was obtained by the reaction of $( \pm)-3$ with $\mathrm{PhMgBr}$ under nitrogen. Bromobenzene $(9.58 \mathrm{ml}, 14.2 \mathrm{~g}$, $0.0910 \mathrm{~mol})$ dissolved in THF $(30 \mathrm{ml})$ was added dropwise to $\mathrm{Mg}$ powder $(2.51 \mathrm{~g}, 0.103 \mathrm{~mol})$ with stirring, and after the addition was completed, the mixture was stirred under reflux for $3 \mathrm{~h}$ to obtain a $\mathrm{PhMgBr}$ solution. A THF
$(60 \mathrm{ml})$ solution of $( \pm)-3(17.0 \mathrm{~g}, 0.0606 \mathrm{~mol})$ was added dropwise to the $\mathrm{PhMgBr}$ solution cooled to room temperature, and then the mixture was refluxed for $3 \mathrm{~h}$. The reaction was terminated by slowly adding $50 \mathrm{ml}$ of water, and the crude product was extracted using diethyl ether-saturated aq $\mathrm{NaCl}$. Removal of the solvent from the organic layer gave crude product. Yield $22 \mathrm{~g}$ $(>100 \%)$. Recrystallization three times from diethyl ether-hexane $(1: 1, \mathrm{v} / \mathrm{v})$ led to pure alcohol. Yield $14.3 \mathrm{~g}$ $(66.0 \%) . \mathrm{mp} 122.5-123.8^{\circ} \mathrm{C} .{ }^{1} \mathrm{H}$ NMR $(400 \mathrm{MHz}$, $\left.\mathrm{CDCl}_{3}, \mathrm{Me}_{4} \mathrm{Si}\right) \delta 8.19-8.15(\mathrm{~m}, 1 \mathrm{H}$, aromatic $\mathrm{H})$, $8.06-8.02(\mathrm{~m}, 1 \mathrm{H}$, aromatic $\mathrm{H}), 7.66-7.60(\mathrm{~m}, 2 \mathrm{H}$, aromatic $\mathrm{H}), 7.46-7.36(\mathrm{~m}, 4 \mathrm{H}$, aromatic $\mathrm{H}), 7.21-7.14$ $(\mathrm{m}, 3 \mathrm{H}$, aromatic $\mathrm{H}), 6.90-6.86(\mathrm{~m}, 2 \mathrm{H}$, aromatic $\mathrm{H})$, $4.80(\mathrm{dd}, 1 \mathrm{H},-\mathrm{CHCH}-, J=10 \mathrm{~Hz}, 0.4 \mathrm{~Hz}), 4.53(\mathrm{dd}, 1 \mathrm{H}$, $-\mathrm{CHCH}-, J=10 \mathrm{~Hz}, 0.4 \mathrm{~Hz}), 2.59(\mathrm{~s}, 1 \mathrm{H},-\mathrm{OH}), 1.55(\mathrm{~s}$, $\left.3 \mathrm{H}-\mathrm{CH}_{3}\right), 1.39 \mathrm{ppm}\left(\mathrm{s}, 3 \mathrm{H},-\mathrm{CH}_{3}\right) . \mathrm{IR}(\mathrm{KBr}) 3479 \mathrm{~cm}^{-1}$ $(-\mathrm{OH})$. FD Mass $m / z=358.2$ (calcd 358.2).

$( \pm)$-IDPDMA was synthesized from $( \pm)-\mathbf{4}$ and methacryloyl chloride. In a 500-ml flask equipped with a dropping funnel was placed $\mathrm{NaH}$ (dispersion in oil, $60 \mathrm{wt} \%)(2.34 \mathrm{~g}, 0.224 \mathrm{~mol}(\mathrm{NaH}))$. THF $(50 \mathrm{ml})$ was introduced with a syringe and the mixture was stirred to remove oil from $\mathrm{NaH}$. After stirring was stopped, the supernatant THF wash was removed with a syringe. Fresh THF $(100 \mathrm{ml})$ was added to the washed $\mathrm{NaH}$, and $( \pm)-4(14.0 \mathrm{~g}, 0.0391 \mathrm{~mol})$ dissolved in $80 \mathrm{ml}$ of THF was added dropwise in a 30 -min period with stirring at room temperature. After the addition was completed, the mixture was refluxed for $3 \mathrm{~h}$ and then was cooled to $0^{\circ} \mathrm{C}$. A THF $(30 \mathrm{ml})$ solution of methacryloyl chloride $(4.6 \mathrm{ml}$, $4.9 \mathrm{~g}, 0.047 \mathrm{~mol})$ was added dropwise to the mixture, and the reaction system was allowed to stand with stirring for $1 \mathrm{~h}$. The reaction mixture was decomposed by carefully adding water $(100 \mathrm{ml})$. $\mathrm{NaCl}$ was added to the quenched mixture until the phase separation of organic (THF) and aqueous layers occurred. The two layers were separated, the aqueous layer was washed with diethyl ether, and the ether wash was combined with the THF layer. Removal of solvents from the combined organic extract dried on $\mathrm{Na}_{2} \mathrm{SO}_{4}$ gave crude crystals. Yield $16 \mathrm{~g}$ $(96 \%)$. Recrystallization once from benzene-diethyl ether $(1: 2, \mathrm{v} / \mathrm{v})$ and twice from benzene-hexane $(1: 2$, $\mathrm{v} / \mathrm{v}$ ) led to pure monomer. Yield $7.1 \mathrm{~g} \mathrm{(43 \% ).} \mathrm{mp}$ 168.0-168.8 C. ${ }^{1} \mathrm{H}$ NMR $\left(400 \mathrm{MHz}, \mathrm{CDCl}_{3}, \mathrm{Me}_{4} \mathrm{Si}\right) \delta$ $7.72(\mathrm{~d}, 1 \mathrm{H}$, aromatic $\mathrm{H}, J=8.0 \mathrm{~Hz}), 7.66(\mathrm{~d}, 1 \mathrm{H}$, aromatic $\mathrm{H}, J=6.4 \mathrm{~Hz}), 7.48(\mathrm{~d}, 1 \mathrm{H}$, aromatic $\mathrm{H}$, 
$J=7.2 \mathrm{~Hz}), 7.38-7.34(\mathrm{~m}, 2 \mathrm{H}$, aromatic $\mathrm{H}), 7.33-7.26$ $(\mathrm{m}, 1 \mathrm{H}$, aromatic $\mathrm{H}), 7.24-7.10(\mathrm{~m}, 7 \mathrm{H}$, aromatic $\mathrm{H})$, 6.27-5.64 (m, 2H, vinyl $\mathrm{H}), 5.43(\mathrm{~d}, 1 \mathrm{H},-\mathrm{CHCH}-$, $J=9.2 \mathrm{~Hz}), 5.28\left(\mathrm{~d}, 1 \mathrm{H},-\mathrm{CHCH}_{-}, J=9.2 \mathrm{~Hz}\right), 1.96(\mathrm{~s}$, $\left.3 \mathrm{H}, \alpha-\mathrm{CH}_{3}\right), 1.64\left(\mathrm{~s}, 3 \mathrm{H},-\mathrm{CH}_{3}\right), 1.59\left(\mathrm{~s}, 3 \mathrm{H},-\mathrm{CH}_{3}\right) . \mathrm{IR}$ (KBr) $1636 \mathrm{~cm}^{-1}(\mathrm{C}=\mathrm{C}), 1725 \mathrm{~cm}^{-1}(\mathrm{C}=\mathrm{O}) . \mathrm{FD} \mathrm{MS}$ $m /==426.0$ (calcd 426.2). Anal. Calcd for $\mathrm{C}_{23} \mathrm{H}_{18} \mathrm{O}_{2}: \mathrm{C}$, $78.85 \%$; H, $6.14 \%$. Found: C, $78.85 \%$; H, $6.17 \%$.

\section{HPLC Resolution of $( \pm)-I D P D M A$}

$( \pm)$-IDPDMA was resolved using a chiral column packed with the $(\mathrm{R}, \mathrm{R})$ Whelk $\mathrm{Ol}^{18}$ (4-(3,5-dinitrobenzamido)tetrahydrophenanthrene covalently bound to 5$\mu \mathrm{m}$ silica gel (pore size $100 \AA))$ stationary phase $(25 \times 0.46$ (i.d.) $\mathrm{cm}$ ) cooled to $-5 \mathrm{C}$ using hexane-2-propanol $(99.5: 0.5, \mathrm{v} / \mathrm{v})$ as an eluent (flow rate $=1.3 \mathrm{ml} \mathrm{min}^{-1}$ ). A sample solution $(0.2 \mathrm{ml})$ containing $2.4 \mathrm{mg}$ of the monomer was injected at a time, and 250 times of separation gave $0.3 \mathrm{~g}$ of $(+)$ - and (-)-isomers. By recrystallization of the monomers from hexane, $0.23 \mathrm{~g}$ of each isomer was obtained. (+)-Isomer: e.e. $\sim 100 \%$; $[\alpha]_{365}^{25}+548 ;[\alpha]_{\mathrm{D}}^{25}+129$ (tetrahydrofuran, $c 0.7$ ). A $\mathrm{CD}$ spectrum of the $(+)$-isomer is shown in Figure 1.

\section{Polvmerization}

The details of polymerization experiments and polymer analyses are the same as those reported in our previous reports. $^{12.13 .19}$

\section{Measurement}

${ }^{1}$ H NMR spectra were taken on a Varian Gemini 2000

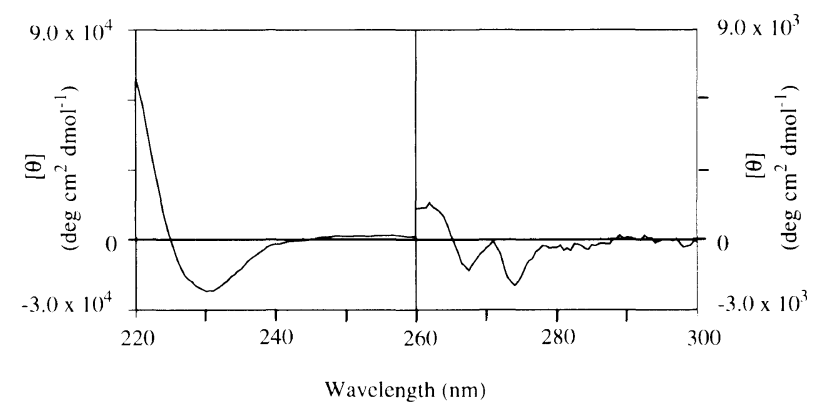

Figure 1. CD spectrum of (+)-IDPDMA with $100 \%$ e.e. [THF, r.t.]. spectrometer ( $400 \mathrm{MHz}$ for ${ }^{1} \mathrm{H}$ measurement). IR spectra were taken on a JASCO FT/IR-7000 spectrometer. Optical rotation was measured with a JASCO DIP-181 polarimeter using a $0.5-\mathrm{dm}$ quartz cell. Circular dichroism (CD) spectra were taken using a JASCO J-720L spectrometer. GPC of poly(IDPDMA) was performed with a Shodex System-21 GPC system equipped with a Shodex UV-41 detector and a JASCO OR-990 polarimetric $\left(\alpha_{\mathrm{Hg}}\right)$ detector using Shodex KF-803 and KF-806F GPC columns connected in series (eluent, THF; flow rate, $1.0 \mathrm{ml} \mathrm{min}^{-1}$; temp, $40^{\circ} \mathrm{C}$ ). A Shodex RI-71S detector was used in place of a Shodex UV-41 detector for the GPC analysis of poly(methyl methacrylate) (PMMA). FD mass spectra were obtained on a JEOL JMS-AX505 spectrometer.

\section{RESULTS AND DISCUSSION}

\section{Durability of Monomer}

Methanolysis reaction of the $( \pm)$-IDPDMA was carried out in $\mathrm{CD}_{3} \mathrm{OD}-\mathrm{CDCl}_{3}(1: 1, \mathrm{v} / \mathrm{v})$ at $35^{\circ} \mathrm{C}$ and monitored by means of ${ }^{1} \mathrm{H}$ NMR spectroscopy in order to determine durability of the ester linkage. The method of experiments has been described in our recent paper. ${ }^{13}$ Higher durability of ester linkage is an important property of a monomer because solvolysis of helical polymethacrylates leads to a loss of the conformation and chiral recognition ability. A pseudo first-order rate constant $(k)$ of $0.025 \mathrm{~h}^{-1}$ and a half-life period $\left(t_{1 / 2}\right)$ of $1637 \mathrm{~min}$ were found for ( \pm )-IDPDMA while $k=0.466$ $\mathrm{h}^{-1}$ and $t_{1 / 2}=89.0 \mathrm{~min}$ have been reported for PDBSMA,${ }^{8,13}$ indicating that the ester linkage of $( \pm)$ IDPDMA is more durable than that of PDBSMA. The isopropylidene group of $( \pm)$-IDPDMA may have a steric effect which prevents methanol molecules from approaching the ester linkage.

\section{Anionic Polymerization}

Anionic polymerization of $( \pm)$ - and ( + )-IDPDMA was carried out using the complexes of $N, N^{\prime}$-diphenylethylenediamine monolithium amide (DPEDA-Li) with (-)-sparteine (Sp), (+)-1-(2-pyrrolidinylmethyl)pyrrolidine (PMP), (+)-2,3-dimethoxy-1,4-bis(dimethylamino)-

Table I. Anionic polymerization of $( \pm)$ - and (+)-IDPDMA using DPEDA-Li complexes at $-78^{\circ} \mathrm{C}^{\mathrm{a}}$

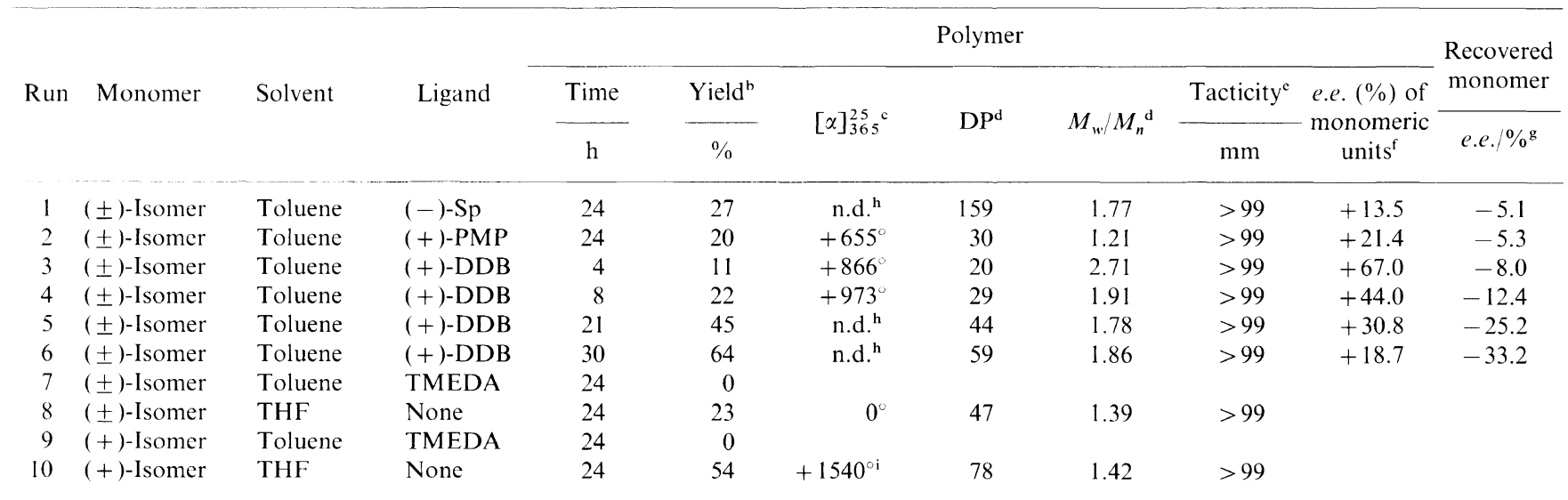

${ }^{\mathrm{a}}[\mathrm{M}] /[\mathrm{I}]=20$; monomer $0.3 \mathrm{~g}$ (runs 1, 2), $0.15 \mathrm{~g}$ (runs 3-6), $0.1 \mathrm{~g}$ (runs 7-10); solvent $9 \mathrm{ml}$ (runs 1, 2), 4.5 ml (runs 3-6), $3 \mathrm{ml}$ (runs 7-10). ${ }^{\mathrm{b}} \mathrm{McOH}$-insoluble part. ${ }^{\mathrm{C}}$ In $\mathrm{CHCl}_{3}$ (conc. $0.5 \mathrm{~g} \mathrm{dl}^{-1}$ ). ${ }^{\mathrm{d}}$ Determined by GPC analysis of PMMAs derived from the original polymers. ${ }^{\mathrm{c}} \mathrm{Determined}$ by $400 \mathrm{MHz}{ }^{1} \mathrm{H}$ NMR analysis of PMMAs derived from the original polymers. ${ }^{\mathrm{f}}$ Calculated from e.e. of the monomer in feed, polymer yield, and e.e. of the remaining monomer. ${ }^{\mathrm{g}}$ Determined by HPLC resolution. ${ }^{\mathrm{h}}$ Polymers were insoluble in $\mathrm{THF}$ or $\mathrm{CHCl}_{3} \cdot{ }^{\mathrm{i}}[\alpha]_{\mathrm{D}}^{25}+353^{\circ}$ 
butane (DDB), and $N, N, N^{\prime} N^{\prime}$-tetramethylethylenediamine (TMEDA) in toluene at $-78^{\circ} \mathrm{C}$ or using DPEDA$\mathrm{Li}$ in tetrahydrofuran at $-78^{\circ} \mathrm{C}$ (Table I). While the polymerization using TMEDA-DPEDA- $\mathrm{Li}$ in toluene did not afford a polymer (runs 7 and 9), the polymerizations under the other conditions resulted in the polymers having a nearly completely isotactic main-chain configuration which suggests that the polymers have a helical conformation.

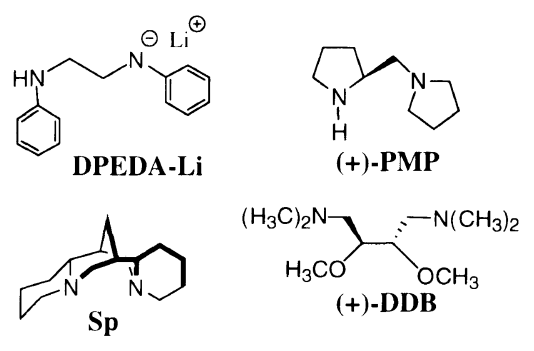

The polymer yields were rather low in most cases but this seems to be based not on unwanted (accidental) quenching of the growing anion but on the relatively low rate of polymerization. This is supported by the results of the polymerization using DDB-DPEDA-Li (runs 3-6) which indicate that the polymer yield increases with the reaction time. The asymmetric anionic polymerization of $\mathrm{PDBSMA}^{8}$ or $\operatorname{TrMA}^{12}$ under similar conditions to those in the present work is known to complete within $24 \mathrm{~h}$ of reaction time: TrMA polymerization using PMP-9-fluorenyllithium under similar conditions to run 2 in Table I completes within $10 \mathrm{~min} .{ }^{12}$ The sluggishness of the reaction may be due to the additional bulkiness of IDPDMA (acetonide moiety) compared with PDBSMA.

Specific rotation of the polymer obtained from the optically pure $(+)$-isomer (run 10) was comparable to that of the single-handed helical poly(TrMA) and larger than that of the starting monomer, suggesting that this polymer may have a single-handed helicity induced by the chirality of the monomer during polymerization. The CD spectral pattern of the polymer was different from that of the monomer but similar to those of single-handed helical poly(PDBSMA $)^{8}$ and poly(TrMA) ${ }^{12}$ especially in the wavelength range below $260 \mathrm{~nm}$ with an intense positive peak at around $240 \mathrm{~nm}$ (Figure 2). The peak intensity of the peak at $240 \mathrm{~nm}$ was smaller than that of the peak at $235 \mathrm{~nm}$ found for the single-handed helical poly(PDBSMA), ${ }^{8}$ but this seems to be due to the overlapping by the negative peak at $230 \mathrm{~nm}$ of the (+)-monomer. Thus, the CD spectrum also supports the single-handed helical structure. GPC analysis of this polymer using UV and polarimetric detections revealed that the optical activity is almost independent from molecular weight and no existence of $(-)$-fraction was confirmed, further supporting the assumption of a single-handed helical conformation. The polymers obtained by the enantiomer-selective polymerization in runs 2,3 , and 4 also showed larger specific rotation values than expected from the e.e. of the monomeric unit: these polymers are also considered to have excess helicity.

In the polymerization of ( \pm )-IDPDMA using the chiral initiators, clear enantiomer selection was observed

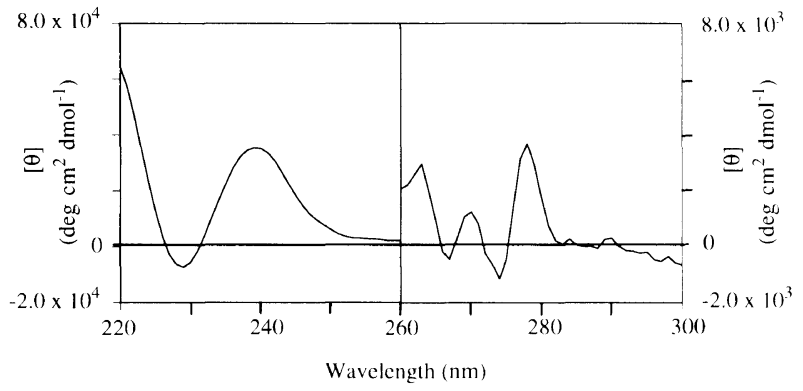

Figure 2. CD spectrum of poly[(+)-IDPDMA $]$ obtained in run 10 in Table I [THF, r.t.].

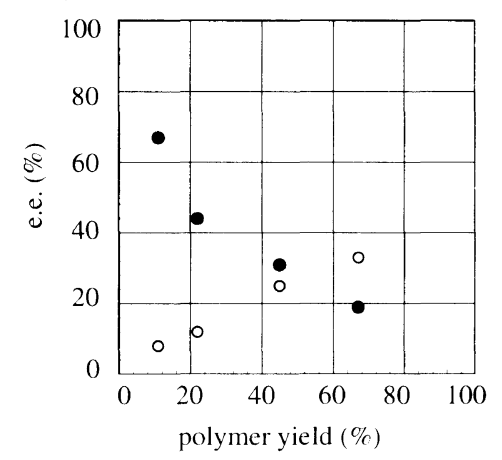

Figure 3. Plots of e.e. of monomeric unit in polymer (O) and unreacted monomer $(\bigcirc)$ against polymer yield in the polymerization of ( \pm )-IDPDMA using DDB-DPEDA-Li (corresponding to the data of runs 3-6 in Table I).

where $(+)$-isomer was preferentially polymerized over $(-)$-isomer. DDB among the three chiral ligands led to the highest selectivity. As a chiral, bulky methacrylate which enables enantiomer-selective and helix-senseselective polymerization by anionic catalysis, phenyl-2pyridyl-o-tolylmethyl methacrylate (PPyoTMA) is known. $^{20}$ The enantiomer selectivity in the $( \pm)$ IDPDMA polymerization using DDB was higher than that in the PPyoTMA polymerization using the same chiral ligand: at a polymer yield of $22 \%$, e.e. of the unreacted monomer was $12.4 \%$ and $8.5 \%$ in the former and the latter cases, respectively. In the enantiomerselective polymerization of PPyoTMA, helical conformation of the growing species had an important role in the selection. ${ }^{16}$ The growing anion in the IDPDMA polymerization system may have a more rigid and complete helical structure than the poly(PPyoTMA) anions having a lower isotacticity ( $\mathrm{mm} 94 \%$ ), which may have a connection with the higher selectivity. However, the enantiomer selectivity observed here is much lower than that in the highly efficient enantiomer-selective polymerization of $\alpha$-methylbenzyl methacrylate (MBMA) using $\mathrm{Sp}$-cyclohexylmagnesium bromide where e.e. of the monomeric unit was $92.7 \%$ at $11 \%$ conversion. ${ }^{21,22}$

Figure 3 shows the changes in e.e. of the monomeric unit in polymer and the unreacted monomer. The e.e. of the monomeric unit incorporated into the polymer chain was higher at a lower polymer yield. This feature is in contrast to the anionic enantiomer-selective polymerization of PPyoTMA using DDB-9-fluorenyllithium where the selectivity increased with the progress of the polymerization until monomer conversion reached $c a$. $30 \%$. ${ }^{19}$ This was attributed to the helix formation of the 
Table II. Free-radical polymerization of IDPDMA using $\alpha, \alpha^{\prime}$-azobisisobutyronitrile in toluene at $60^{\circ} \mathrm{C}^{\mathrm{a}}$

\begin{tabular}{|c|c|c|c|c|c|c|c|}
\hline \multirow{3}{*}{ Run } & \multirow{3}{*}{$\begin{array}{l}\text { e.e. }(\%) \text { of } \\
\text { monomer in } \\
\text { feed }^{\mathrm{b}}\end{array}$} & \multicolumn{5}{|c|}{ Polymer } & \multirow{3}{*}{$\frac{\begin{array}{c}\text { Recovered } \\
\text { monomer }\end{array}}{\text { e.e } / \% \mathrm{~b}}$} \\
\hline & & \multirow{2}{*}{$\frac{\text { Yield }^{\mathrm{e}}}{\%}$} & \multirow{2}{*}{$D P^{\mathrm{d}}$} & \multirow{2}{*}{$M_{w} / M_{n}^{\mathrm{d}}$} & \multirow{2}{*}{$\frac{\text { Tacticity } / \%{ }^{\mathrm{f}}}{\mathrm{mm}}$} & \multirow{2}{*}{$\begin{array}{l}\text { e.e. }(\%) \text { of } \\
\text { monomeric } \\
\text { units }^{\mathrm{e}}\end{array}$} & \\
\hline & & & & & & & \\
\hline 1 & 0 & 75 & 202 & 1.94 & $>99$ & 0 & 0 \\
\hline 2 & -23.8 & 63 & 106 & 1.69 & $>99$ & -28.9 & -14.9 \\
\hline 3 & -48.0 & 63 & 162 & 2.71 & $>99$ & -58.9 & -29.8 \\
\hline 4 & -64.7 & 59 & 128 & 1.91 & $>99$ & -78.0 & -46.0 \\
\hline 5 & -74.0 & 61 & 121 & 1.78 & $>99$ & -82.3 & -61.1 \\
\hline 6 & +100 & 28 & 217 & 1.86 & $>99$ & +100 & +100 \\
\hline
\end{tabular}

${ }^{\mathrm{a}}[\mathrm{M}] /[\mathrm{I}]=50$, monomer $0.1 \mathrm{~g}$, toluene $2.3 \mathrm{ml}$, time $24 \mathrm{~h} .{ }^{\mathrm{b}}$ Determined by HPLC resolution. ${ }^{\mathrm{c}}$ Hexane-insoluble part. ${ }^{\mathrm{d}}$ Determined by GPC analysis of PMMAs derived from the original polymers. ${ }^{e}$ Calculated from e.e. of the monomer in feed, polymer yield, and e.e of the remaining monomer. ${ }^{6}$ Determined by $400 \mathrm{MHz}{ }^{1} \mathrm{H}$ NMR analysis of PMMAs derived from the original polymers.

polymer chain in the early stages of polymerization which enhances the enantiomer selectivity. In the present reaction systems, helix may be completely built up at a lower polymer yield $(<10 \%)$ (for lower DP of the growing anion), and this may be why the effects of polymer yield on enantiomer-selectivity was not clearly observed.

\section{Free-Radical Polymerization}

The conditions and results of radical polymerization of IDPDMA having various e.e.'s are summarized in Table II. The obtained polymers were nearly completely isotactic regardless of the e.e. of the starting monomer, suggesting that the polymers have a helical structure. Although the obtained polymers were mostly insoluble in solvents such as toluene, THF, chloroform, dimethylsulfoxide, and $N, N$-dimethylformamide, a small amount $(9 \mathrm{wt} \%)$ of THF-soluble part $\left(\mathrm{DP}=37, M_{w} / M_{n}=1.09\right)$ was obtained from the polymerization products of optically pure (+)-IDPDMA (run 6). The THF-soluble polymer showed CD absorptions (Figure 4) whose spectral pattern and band intensity were different from those of the spectrum of (+)-IDPDMA. The spectrum has the characteristics of both the spectrum of (+)-IDPDMA (Figure 1) and that of the poly $[(+)$ IDPDMA] prepared by anionic polymerization (Figure 2): It has a negative peak at $230 \mathrm{~nm}$ and a positive peak at $240 \mathrm{~nm}$ whose intensity is smaller than those of the corresponding peaks of the $(+)$-IDPDMA and the poly $[(+)$-IDPDMA], respectively. These observations suggest that the chiroptical properties of the THF-soluble poly $[(+)$-IDPDMA] are based on both the chiral structure of the ester group and the main-chain helical conformation with excess single-handed helicity which was induced by the effect of the chiral ester group during the radical polymerization process. However, the helixsense excess of the poly[(+)-IDPDMA] prepared by radical polymerization appears to be lower than that of the polymer obtained by anionic polymerization based on the CD spectrum.

Another interesting aspect of the polymerization of IDPDMA is enantiomer selection. Figure 5 shows the relationship between the e.e.'s of the recovered monomer and the monomeric unit in polymer and that of the starting monomer. The e.e. of the recovered monomer was always lower and that of the monomeric unit in polymer was always higher than that of the starting

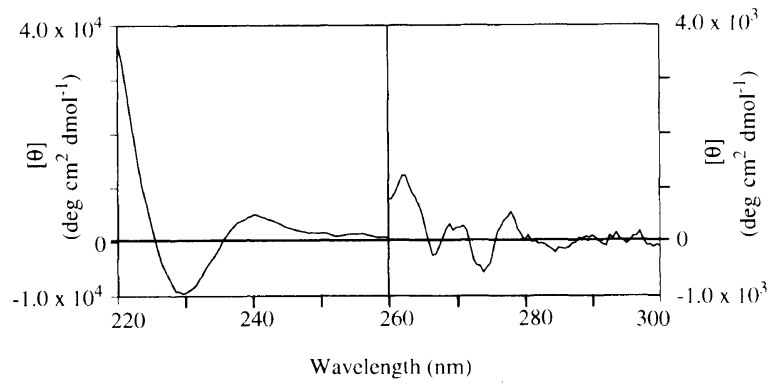

Figure 4. $\mathrm{CD}$ spectrum of THF-soluble poly[(+)-IDPDMA $]$ obtained in run 6 in Table II [THF, r.t.].

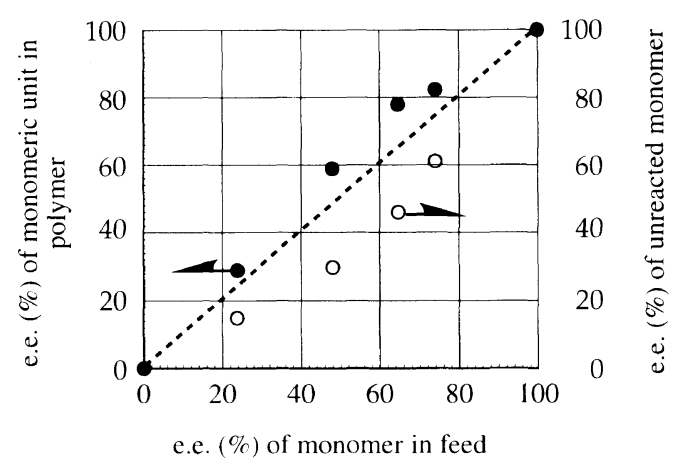

Figure 5. Relation between e.e. (absolute value) of monomeric unit in polymer $(O)$ and unreacted monomer $(O)$ and that of monomer in feed corresponding to the data shown in Table II.

monomer, indicating that the enantiomer in excess was preferentially incorporated into the polymer chain, i.e., enantiomer-selective polymerization took place. The enantiomer selection may be governed by the excess helicity of the growing radical. The growing species consisting of excess enantiomeric component of monomeric units probably takes helical conformation with excess helix sense which can choose one enantiomer of IDPDMA over the other.

Enantiomer selection has been also found in the free-radical polymerization of PPyoTMA with various e.e.'s. ${ }^{19}$ However, in the polymerization of PPyoTMA with $-53.4 \%$ e.e., the e.e. of the recovered monomer at $95.5 \%$ polymer yield was rather close to that of the starting monomer $(-50.3 \%)^{19}$ while in the polymerization of IDPDMA with a similar e.e. $(-48.0 \%)$ at a lower polymer yield (63\%) (run 3 ), the difference between the e.e. of the starting monomer and that of the recovered 
monomer was much larger compared with that in the polymerization of PPyoTMA. This indicates that the enantiomer selectivity in the polymerization of IDPDMA is much higher than that in the polymerization of PPyoTMA. The higher selectivity may be ascribed to a higher regularity of the growing species in the IDPDMA polymerization due to the highly isotactic structure.

The enantiomer selectivity observed in the radical polymerization is lower than those observed for the anionic polymerization of several racemic methacrylates including MBMA using optically active initiator complexes where coordination of monomer to counter cation has an important role in enantiomer selection. ${ }^{22}$ The absence of coordination mechanism in free-radical polymerization is considered to be responsible for the rather low selectivity.

\section{CONCLUSION}

We synthesized a novel chiral methacrylate, $( \pm)$ IDPDMA, and resolved it into optically active form. IDPDMA gave highly isotactic polymers by free-radical polymerization at $60^{\circ} \mathrm{C}$ as well as anionic polymerization at $-78^{\circ} \mathrm{C}$. Chiroptical properties of the polymers derived from (+)-IDPDMA with $100 \%$ e.e. by the anionic and free-radical polymerizations suggested that the polymerization was helix-sense-selective. The anionic polymerization of $( \pm)$-IDPDMA using the chiral initiators was enantiomer-selective; the selectivity in the polymerization using DDB as a chiral ligand was higher than that for the PPyoTMA polymerization under similar conditions. Enantiomer selection was also observed in the radical polymerization of optically active IDPDMA with various e.e.'s; the selectivity was much higher than that found in the polymerization of PPyoTMA under similar conditions, which had been the only example of enantiomer-selective radical polymerization, ${ }^{10}$ and is probably the highest observed for a free-radical polymerization system.

Acknowledgments. This work was supported in part by the New Energy and Industrial Technology Development Organization (NEDO) under the Ministry of International Trade and Industry (MITI), Japan, through the grant for "Precision Catalytic Polymerization" in the Project "Technology for Novel High-Functional Material"' (1996-2000). The authors thank Dr. K. Ma- tsumoto (Nagoya University) for mass spectrometric analyses and Mr. Y. Sato (Nagoya University) for his experimental assistance.

\section{REFERENCES AND NOTES}

1. Y. Okamoto and T. Nakano, Chem. Re'.. 94, 349 (1994).

2. (a) T. Nakano and Y. Okamoto, in "The Polymeric Materials Encyclopedia," J. C. Salamone, Ed., CRC Press, FL, 1996, pp 417-423. (b) T. Nakano and Y. Okamoto, in "Catalysis in Precision Polymerization." S. Kobayashi, Ed.. John Wiley \& Sons. Chishester, Sussex, 1997, pp 271-309.

3. Y. Okamoto, CHEMTECH. 144, (1987).

4. Y. Okamoto and K. Hatada, J. Liq. Chromatogr., 9, 369 (1986).

5. T. Nakano, M. Mori, and Y. Okamoto, Macromolecules, 26, 867 (1993).

6. (a). Nakano, A. Matsuda, and Y. Okamoto, Polym. J., 28, 556 (1996). (b) H. Yuki, K. Hatada, T. Niinomi, and Y. Kikuchi, Polym. J., 1, 36 (1970).

7. (a) T. Nakano. Y. Shikisai, and Y. Okamoto, Polym. J., 28, 51 (1996). (b) T. Nakano, Y. Shikisai, and Y. Okamoto, Proc. Japan Acad., 71. Ser. B, 251 (1995).

8. T. Nakano, A. Matsuda, M. Mori, and Y. Okamoto, Polym. J., 28, 330 (1996).

9. T. Nakano and Y. Okamoto, in "Controlled Radical Polymerization," ACS Symposium Series 685, K. Matyjazsewski, Ed., ACS, Washington, D.C., 1998, pp 451-462.

10. K. Hatada, T. Kitayama, and K. Ute, Prog. Polym. Sci., 13, 189 (1988).

11. T. Nakano and Y. Okamoto, Macromolecules, in press.

12. T. Nakano, Y. Okamoto, and K. Hatada, J. Am. Chem. Soc.. 114, 1318 (1992).

13. T. Nakano, Y. Satoh, and Y. Okamoto, Polym. J., 30, 635 (1998).

14. S. Krishnan, D. G. Kuhn, and G. A. Hamilton, J. Am. Chem. Soc., 99, 8121 (1977).

15. F. Hoffmann-La Roche, Netherlands Appln. 6,600,200 (1996) [Chem. Abstr., 65, 15297 (1966)].

16. G. L. Buchanan and D. B. Jhaveri, J. Org. Chem., 26, 4295 (1961).

17. F. Wudl, T. Sukuki, and M. Prato, Sith. Met., 59, 297 (1993).

18. (a) W. H. Pirkle and C. J. Welch, Tetrahedron Asymmetry, 5, 777 (1994). (b) W. H. Pirkle and C. J. Welch, J. Liq. Chromatogr.. 15, 1947 (1992).

19. Y. Okamoto, M. Nishikawa, T. Nakano, E. Yashima, and K. Hatada, Macromolecules, 28, 5135 (1995).

20. E. Yashima, Y. Okamoto, and K. Hatada, Polym. J., 19, 897 (1987).

21. For a review, see: Y. Okamoto and E. Yashima, Prog. Polym. Sci., 15, 263 (1990).

22. (a) Y. Okamoto, K. Urakawa, and H. Yuki, Macromolecules, 11, 719 (1978). (b) Y. Okamoto, K. Ohta, and H. Yuki, Macromolecules, 11, 724 (1978). (c) Y. Okamoto, K. Suzuki, T. Kitayama, H. Yuki, H. Kageyama, K. Miki, N. Tanaka, and N. Kasai, J. Am. Chem. Soc., 104, 4618 (1982). (d) Y. Okamoto, K. Urakawa, and H. Yuki, J. Polvm. Sci., Polym. Chem., 19, 1385 (1981). 